\title{
Ducted Savonius Turbine Performance: A Multi-Application Approach
}

\author{
Sebastian Brusca ${ }^{1, *}$, Fabio Famoso ${ }^{1}$, Antonio Galvagno ${ }^{1}$, Rosario \\ Lanzafame $^{2}$, Stefano Mauro ${ }^{2}$, Michele Messina ${ }^{2}$, Mauro Prestipino ${ }^{1}$ \\ 1University of Messina, Engineering Department, 98166 Messina, Italy \\ 2University of Catania, Civil Engineering and Architecture Department, 95125 Catania, Italy
}

\begin{abstract}
In the last decades, the public opinion has paid great attention to environmental pollution and global warming. Energy sector has a strong impact on environment. Thus, the use of renewable energies is becoming mandatory. The present paper deals with a study of ducted Savonius turbine performance as a function of geometric and operating parameters. Ducted turbines could be used as power take-off in multiple applications. In this paper, two main applications were studied. The first application is related to the possibility to install the turbine inside building with the purpose of architectonic integration of the system. The second one is related to wave energy harvesting. In both cases the same type of turbine was used to convert input energy (wind or wave energy) into electricity. Turbine performance were studied as a function of turbine overlap ratio, as well as air flux oscillating frequencies. On the basis of the obtained results, turbine performance increase in ducted configuration and a change in best overlap ratio was registered.
\end{abstract}

\section{Introduction}

In the last century an indiscriminate exploitation of energy sources has been made with the consequence of pollution and global worming dramatically increase. Strategies to slow down and even stop these problems should be considered in worldwide energy policies. Alternatives to reduce conventional energy sources utilization and its impacts are certainly the introduction of renewable energy in the energy scenario and decentralized power generation as a policy to reduce transportation waste. These strategies will contribute to a sustainable development of societies.

Wind energy extraction in urban areas is a very interesting method for energy supply. Moreover, energy generation takes place directly in energy end

\footnotetext{
* Corresponding author: sbrusca@unime.it
} 
use site with a decentralization of power generation: the essence of embedded generation $[1-4]$.

Savonius turbine could be suitable for exploiting wind energy in urban areas due to the low wind velocity operation, low installation costs and relatively high efficiency. In order to increase turbine efficiency, building mounted ducted wind turbine could be an interesting method to increase turbine performance in terms of generated power and efficiency [5-7].

Another interesting method to reduce conventional energy sources utilization and to reduce the impact on environment is sea energy. In particular, wave energy is the most promising energy source.

Oscillating Water Column (OWC) systems are one of the most popular technologies for wave energy conversion $[8,9]$. They consist of a partially submerged chamber with an underwater opening on its front and an air turbine. Waves impinging on the device cause the water column inside the chamber to oscillate, which gives its name to the system. As a result of these oscillations, the water column acts like a piston, forcing the air in the upper part of the chamber to flow alternatively out of the chamber and into it, driving the turbine in the process.

Again, Savonius turbine could be used to exploiting wave energy source operating as a power take-off in the OWC systems.

In the present paper a study on ducted Savonius turbine was carried out with a multi-application purpose. In particular, turbine performances were studied as a function of turbine overlap ratio and air flux oscillation frequency.

In this paper ducted Savonius turbines were used into two main applications.

The first one is related to wind energy harvesting. In particular, ducted turbine could be used in building mounted applications.

The second one is related to wave energy harvesting. In this particular application ducted Savonius could be used as the power take-off in OWS systems.

\section{Experimental Setup}

In the present paragraph a brief description of the experimental setup is given, as well as torque measurement method.

In order to measure turbine torque, a simple band brake was implemented and used. The brake is used to apply the load to the turbine shaft, controlling the turbine rotational speed at its operating condition, as well as to measure turbine torque. Figure 2 shows a schema of the proposed brake.

The band brake consists of the following components:

1. a pulley

2. a nylon-coated metal wire

3. a suspended mass

4. a load cell

Referring to Fig. 1(a), the turbine rotor and its shaft are supported by bearings and are rotationally free. The pulley is joined to the turbine shaft and rotates in solidarity with turbine rotor. A nylon-coated metal wire is joined to a load cell fixed to the ground, it passes over the pulley and suspends a mass at the other end. Varying the suspended mass, it is possible to regulate turbine 
load and control its rotational speed. By measuring forces with the load cell and turbine rotational speed, it is possible to calculate turbine torque and power. In Fig. 1(b), a dynamic forces balance is shown. In the figure, $F_{t}$ represents the weight force of the mass $m$, while $F_{m}$ is the force measured by the load cell and $F_{f}$ is the friction force over the pulley. In static condition $F_{m}$ is equal to $F_{l}$, while in dynamic condition $F_{m}$ is equal to the sum of $F_{l}$ and $F_{f}$. Therefore, it is possible to calculate friction force $F_{f}$ and then turbine torque using pulley radius $R_{p}$. Main brake characteristics are reported in Table 1 .

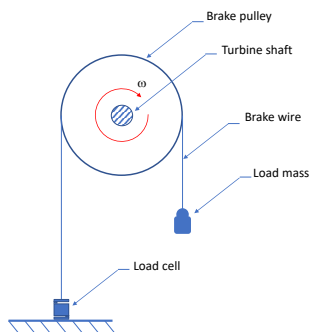

(a)

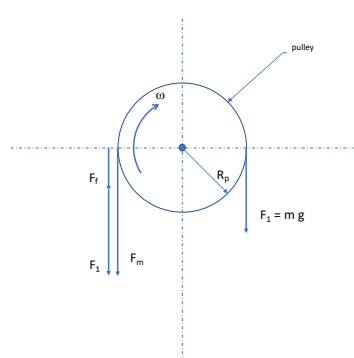

(b)

Fig. 1. Schema of the implemented band brake

Table 1. Main band brake characteristics

\begin{tabular}{cc}
\hline Parameter & Description \\
\hline & Radius \\
Brake pulley & $11 \mathrm{~mm}$ \\
& Material \\
& Alluminum \\
Load mass & Mass \\
& $0 \div 10 \mathrm{~g}$ \\
Brake wire & Material \\
& Nylon-coated metal \\
Load cell & $\pm 1 \mathrm{~N}$ \\
\hline
\end{tabular}

As far as the bare turbine tests, they were carried out by means of a wind tunnel. The latter is a closed loop wind tunnel with the testing section of $500 \times 500 \times 1200 \mathrm{~mm}$. Air velocity in the testing section can vary in the range 0 to $30 \mathrm{~m} / \mathrm{s}$ with a turbulence level of $1 \%$ [ [10].

In order to measure ducted air turbine performance, an ad hoc experimental setup was built and used. It consists essentially of a prismatic air tube (testing tube) in which turbine runs. The testing tube is $100 \mathrm{~mm}$ high, $100 \mathrm{~mm}$ wide, $1000 \mathrm{~mm}$ length and it is made of transparent materials to allow Particle Image Velocimetry (PIV). An air generator blows air with an imposed velocity into the testing tube. Fig. 2 shows a schema and a photograph of the implemented experimental setup. The experimental setup was designed to have the possibility of an alternated flow into the testing tube. 


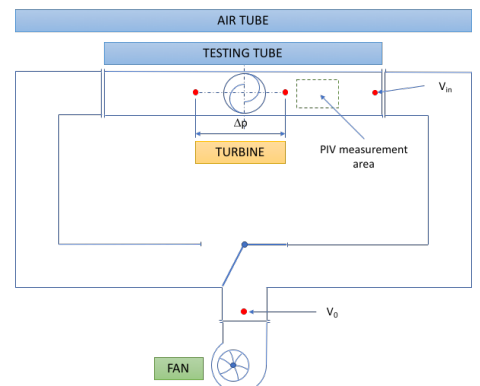

(a)

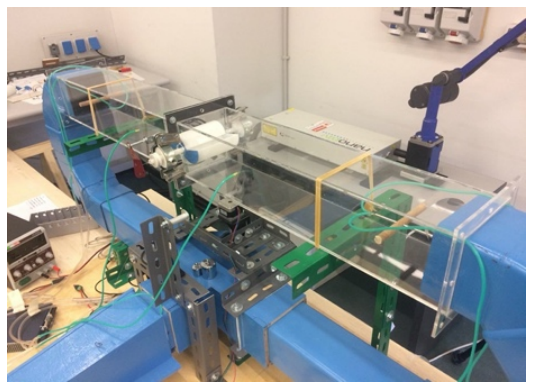

(b)

Fig. 2. Experimental setup: (a) schema, (b) photograph

The fan (see Fig. 2(a)) blows air into the air tube and a divider could deflects air flow in one direction or in another. The air velocity can be controlled varying fan rotational speed. With reference to Fig. 2(a), the velocities at the air tube entrance $\left(V_{o}\right)$ and at testing tube end $\left(V_{i n}\right)$ were measured using pitot tubes and pressure sensors. In the same manner, static pressure drop across the turbine $(\Delta p)$ was measured using pressure sensors at one dimeter distance from the turbine. Velocity flow field in the testing tube measurement was carried out by means of Particle Image Velocimetry.

Particle Image Velocimetry (PIV) is an optical method to measure flow field with particular attention to velocity field [11]. This method is used widely to obtain instantaneous velocity measurements and related fluid properties. The fluid has to be seeded with small tracing particles, which are assumed to realistically follow the flow dynamics (the Stokes number is the degree to which the particles faithfully follow the flow). As far as the seeding it is concerned, an air atomizer was used to create small oil droplets in the flow filed. The Stoke number of the seeding was maintained lower than 0.1, so that the oil droplets follow fluid streamlines closely. An ion laser illuminates the fluid and the entrained particles, so that particles are visible. Two dual frames cameras register images sequence and the motion of the seeding particles is used to calculate velocity and direction (the velocity field) of the flow under study.

\section{Materials and Methods}

The effects of flux oscillation frequency and turbine overlap ratio on ducted turbine performance was studied using an ad hoc experimental setup. Savonius type air turbines were tested to verify turbine performance in both applications: building mounted air turbine and OWC power take-off.

In particular, turbines with an aspect ratio equal to 1 and different overlap ratios $(\mathrm{OR}=0,1 / 6,1 / 3,1 / 2)$ were tested. In Fig. 3 and Table 2 main geometric characteristics are reported. 


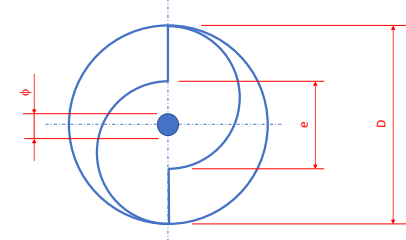

(a)

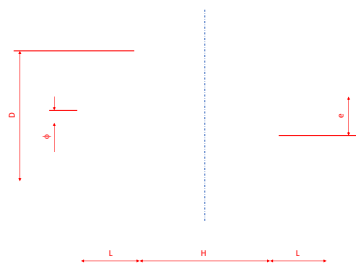

(b)

Fig. 3. Turbine main geometric parameters

Table 2. Turbine main geometric parameters.

\begin{tabular}{cc}
\hline Parameter & Value \\
\hline Turbine diameter (D) & $90 \mathrm{~mm}$ \\
Turbine height (H) & $90 \mathrm{~mm}$ \\
Turbine gap (e) & $15 \mathrm{~mm}$ \\
Overlap ratio (OR) & $0,1 / 6,1 / 3,1 / 2$ \\
Aspect ratio (AR) & 1 \\
Turbine axis diameter $(\phi)$ & $10 \mathrm{~mm}$ \\
Turbine axis length (L) & $60 \mathrm{~mm}$ \\
\hline
\end{tabular}

All tested turbines were realized with an additive manufacturing method $[12,13,14]$ and have an aspect ratio equal to 1 and diameter and height were determined to fit testing tube, with a blockage ratio of 0.81 .

All turbine time-varying parameters have been averaged using the method described by Setoguchi in [15]. Turbine power coefficient as a function of tip speed ratio, and turbine power as a function of rotational speed were determined.

$$
\begin{gathered}
\overline{v_{a}}=\frac{1}{T} \int_{0}^{T}\left|v_{a}\right| d t \\
\overline{\Delta p}=\frac{1}{T} \int_{0}^{T}|\Delta p| d t \\
\bar{\omega}=\frac{1}{T} \int_{0}^{T}|\omega| d t \\
\bar{M}=\frac{1}{T} \int_{0}^{T}\left|F_{n}\right| R_{p} d t
\end{gathered}
$$

where $v_{a}$ is the instantaneous turbine upstream air velocity, $\Delta p$ is the instantaneous pressure drop across the turbine, $w$ is the instantaneous turbine rotational speed, $M$ is the turbine torque, while $F_{n}$ and $R_{p}$ are the total force and pulley radius, respectively. The overlined variables represent the averaged values. Moreover, $T$ is the wave period. 
The average power generated by the turbine can be calculated using Eq. (5).

$$
\bar{P}=\bar{M} \bar{\omega}
$$

Calculated average power, average upstream velocity and pressure drop, turbine power coefficient comes out (see Eq. (6)).

$$
C p=\frac{\bar{P}}{\frac{1}{2} \varrho \Omega_{T} \overline{v_{a}^{3}}+\Omega_{T} \overline{\Delta p} \overline{v_{a}^{3}}}
$$

where $\Omega_{r}$ is the turbine swept area, $\rho$ is the air density, while $C_{p}$ is the average power coefficient. Power coefficient was determined as a function of Tip Speed Ratio (see Eq. 7).

For each flux oscillation frequency $(0.1,0.5,1.0$, and $1.5 \mathrm{~Hz})$ and overlap ratios $(\mathrm{OR}=0,1 / 6,1 / 3,1 / 2)$ and peak velocity $(5 \mathrm{~m} / \mathrm{s}), 5$ repetitions were carried out.

$$
\lambda=\frac{\omega R_{T}}{\overline{v_{a}}}
$$

All the experiments reported in the present paper were carried out using a fixed blockage ratio (ratio between turbine swept area and duct cross-section area). This parameter was maintained at $81 \%$.

\section{Results and Discussion}

In Fig. 4 turbine power coefficient as a function of tip speed ratio as well as turbine power versus rotational speed are shown for both turbine configurations and for all studied turbine overlap ratios.

As it is possible to observe in Fig. 4(b), ducted configuration allows higher power extraction and it happens for all turbine overlap ratios. Increased power is probably due to the blockage effect imposed by the turbine rotation. Pressure contribution allows an increase in power more than five times the power obtained with the same turbine bare. Increased power allows higher power coefficients except for a null value of the turbine overlap ratio (see Fig. 4(a)).

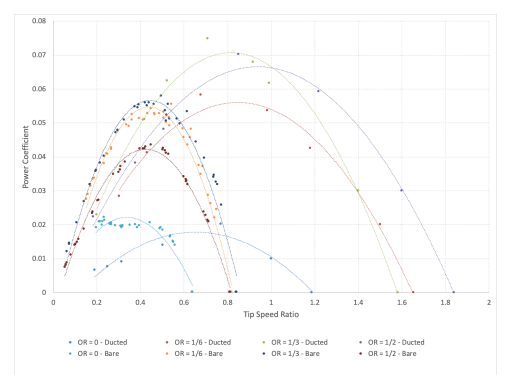

(a)

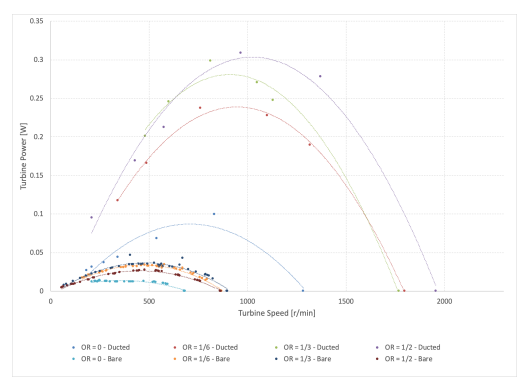

(b)

Fig. 4. Turbine performance ratio for different overlap ratios both in ducted and bare configuration: (a) Power Coefficient versus Tip Speed Ratio; (b) Turbine Power versus Rotational Speed. 
As it is possible to observe in Fig. 5, where maximum power coefficients are reported as a function of turbine overlap ratio, best turbine OR equal to $1 / 3$ for both turbine configurations. For that OR an increase of about $40 \%$ is registered in ducted configuration. Thus, considering the building mounted application of ducted turbine, form a design point of view the best choice is again $\mathrm{OR}=1 / 3$.

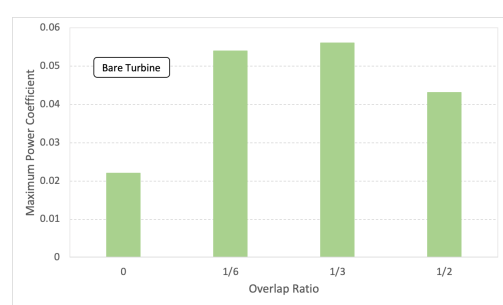

(a)

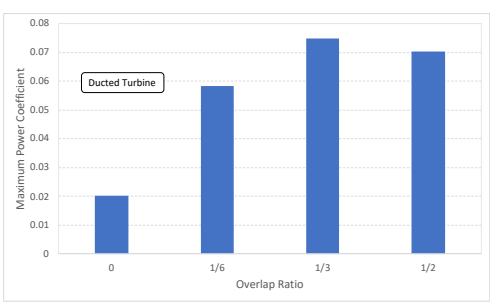

(b)

Fig. 5. Maximum Power Coefficient as a function of turbine Overlap Ratio for both turbine configurations: (a) Bare Turbine; (b) Ducted Turbine.

Considering ducted turbine in an oscillating air flux, turbine power coefficient as a function of tip speed ratio for different turbine overlap ratios and air flux oscillation frequencies are reported in Fig. 6.

As it is possible to observe in the figure, a variation of the turbine power coefficient variation as a function of turbine overlap ratio. Taking into account turbine performance with a fixed air flux (air flux frequency equal to 0 ), an increase of turbine power coefficient is evident. This occurs for all overlap ratios and all air flux frequencies.

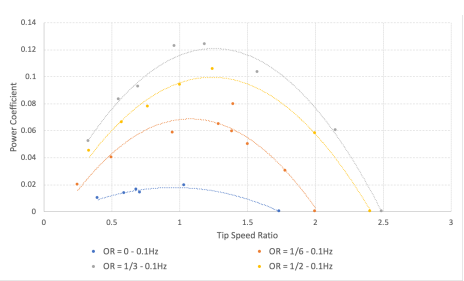

(a)

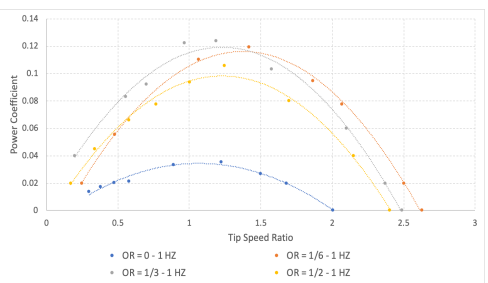

(c)

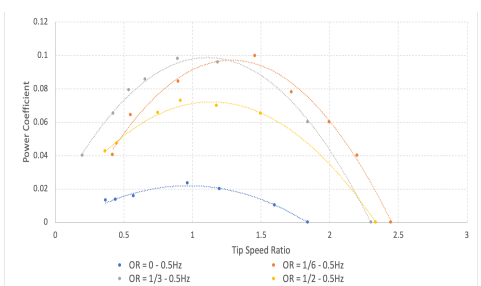

(b)

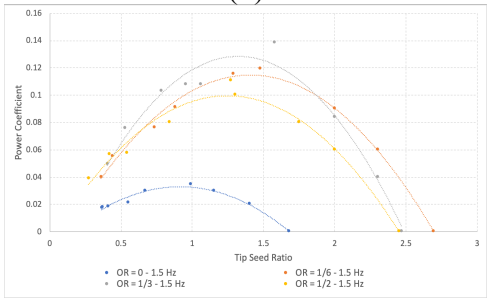

(d)

Fig. 6. Ducted Turbine Power Coefficient as a function of Tip Speed Ratio for different Overlap Ratios and air flux oscillation frequency: (a) $\mathrm{FF}=0.1 \mathrm{~Hz}$; (b) FF $=0.5 \mathrm{~Hz}$; (c) $\mathrm{FF}=1 \mathrm{~Hz}$; (d) $\mathrm{FF}=1.5 \mathrm{~Hz}$. 
Comparing maximum value of turbine power coefficient between both applications, it is also evident an increase of the maximum value of the turbine power coefficient of about $70 \%$ for all studied air flux frequencies (see Fig. 7).

Differently to the fixed air flux case, maximum power coefficient occurs for a turbine overlap ratio equal to $1 / 3$.

Thus, from a design point of view the best turbine overlap ratio in the OWC application is $1 / 3$.

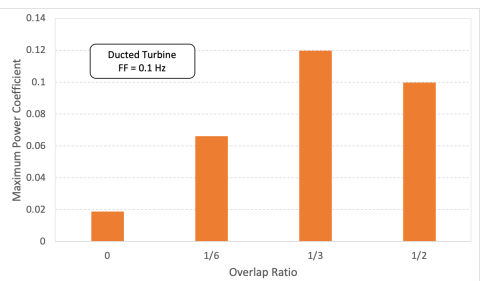

(a)

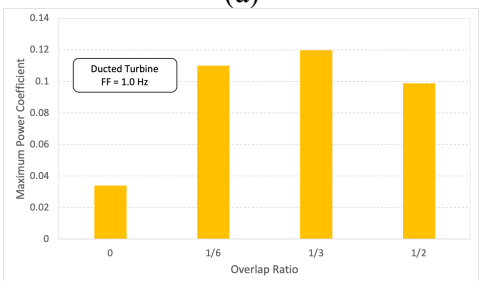

(c)

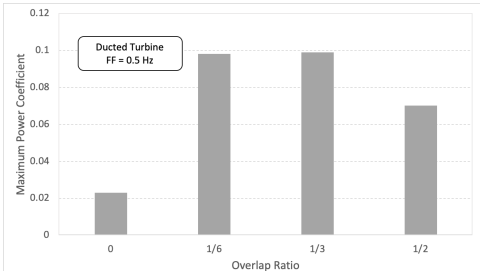

(b)

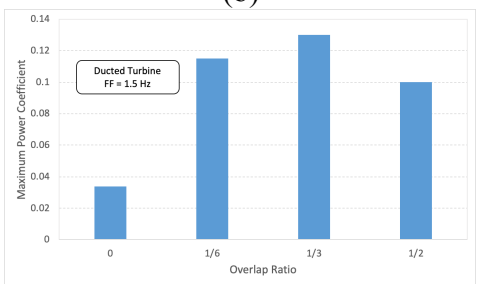

(d)

Fig. 7. Ducted Turbine Maximum Power Coefficient as a function of turbine Overlap Ratios for different air flux oscillation frequency: (a) FF $=0.1 \mathrm{~Hz}$; (b) FF = $0.5 \mathrm{~Hz}$; (c) $\mathrm{FF}=1 \mathrm{~Hz}$; (d) FF $=1.5 \mathrm{~Hz}$.

\section{Conclusions}

The focus of the present paper is the performance analysis of a Savonius type air turbine in ducted configuration.

Ducted turbine can be used in two main applications: wind turbine in building mounted application; power take-off in OWC systems.

Turbine performances were determined as a function of turbine overlap ratio $(0,1 / 6,1 / 3,1 / 2)$ and air flux frequency $(0,0.1,0.5,1.0 \mathrm{~Hz})$.

An ad hoc experimental setup was implemented to test turbine performance in both applications. done:

On the basis of the presented results the following considerations can be

1. Ducting the turbine an increase of extracted power is registered;

2. An increase of turbine power coefficient is also evident;

3. The optimum turbine overlap ratio is about $1 / 3$ in both bare and ducted configurations for a monodirectional air flux;

4. Turbine performances in the OWC (running in an oscillating air flux) result increased for all overlap ratios and for all air flux frequencies; 
5. The best overlap ratio in the OWC application resulted equal to $1 / 3$.

\section{Acknowledgements}

The research is supported by "programma ricerca di ateneo UNICT 2020--22 linea 2 " of the University of Catania.

\section{References}

[1] L. Ledo, P. B. Kosasih, P. Cooper, Roof mounting site analysis for micro-wind turbines, Renewable Energy, 36, (2011)

[2] F. Balduzzi, A. Bianchini, L. Ferrari, Microeolic turbines in the built environment: Influence of the installation site on the potential energy yield, Renewable Energy, 45, (2012).

[3] S. Mertens, The energy yield of roof mounted wind turbines, Wind Engineering, 27, (2003).

[4] J. Knight, Urban wind power: breezing into town, Nature, 430, (2004).

[5] S. Mauro, S. Brusca, R. Lanzafame, M. Messina, CFD modelling of a ducted Savonius wind turbine for the evaluation of the blockage effects on rotor performance, Renewable Energy, 141, (2019).

[6] N. Thakur, A. Biswas, Y. Kumar, M. Basumatary, CFD analysis of performance improvement of the Savonius water turbine by using an impinging jet duct design, Chinese Journal of Chemical Engineering, 27, (2019).

[7] N. K. Sarma, A. Biswas, R. D. Misra, Experimental and computational evaluation of Savonius hydrokinetic turbine for low velocity condition with comparison to Savonius wind turbine at the same input power, Energy Conversion and Management, 83, (2014).

[8] U. Senturk, A. Ozdamar, Wave energy extraction by an oscillating water column with a gap on the fully submerged front wall. Applied Ocean Research, 37, (2012).

[9] Y. Zhang, Q. Zou, D. Greaves, Air-water two-phase flow modelling of hydrodynamic performance of an oscillating water column device. Renewable Energy, 41, (2012).

[10] S. Brusca, R. Lanzafame, M. Messina, Low-speed wind tunnel: Design and build in Wind Tunnels: Aerodynamics, Models and Experiments, edited by J. D. Pereira (Nova Publisher Inc., New York, 2011).

[11] M. Raffel, C. Willert, S. Wereley, J. Kompenhans, "Particle Image Velocimetry: A Practical Guide", (2007) Springer, Berlin Heidelberg.

[12] A. Visco, C. Scolaro, A. Quattrocchi, R. Montanini, Response to fatigue stress of biomedical grade polyethylene joints welded by a diode laser. Journal of the Mechanical Behavior of Biomedical Materials, 86, (2018).

[13] R. Montanini, A. Quattrocchi, S. A. Piccolo, A. Amato, S. Trocino, S. C. Zignani, M. Lo Faro, G. Squadrito, Real-time thermal imaging of solid oxide fuel cell cathode activity in working condition. Applied Optics, 55, (2016).

[14] A. Visco, C. Scolaro, T. Terracciano, R. Montanini, A. Quattrocchi, L. Torrisi, N. Restuccia, Static and dynamic characterization of biomedical 
polyethylene laser welding using biocompatible nano-particles. EPJ Web of Conferences, 167, (2018).

[15] T. Setoguchi, S. Santhakumar, H. Maeda, M. Takao, K. Kaneko, A review of impulse turbines for wave energy conversion, Renewable Energy, 23, (2001). 